\title{
Reflexions about the COVID-19 Pandemic
}

\author{
Gilson Soares Feitosa ${ }^{1 *}$ \\ ${ }^{1}$ Teachig and Research Director of Santa Izabel Hospital of Santa Casa de Misericordia da Bahia; \\ Medicine Professor of Escola Bahiana de Medicina e Saúde Pública; Salvador, Bahia, Brazil
}

The world has been surprisely caught by an unprecedent pandemic in the last 100 years.

Of course we are all aware of the bubonic plague in the middle age that killed a significant number of the human inhabitants at the time. Also we know the suffering imposed by recurrent pandemic smallpox which took many lives since ancient ages and from which we justly got rid of, eliminating new cases in any part of the word since 1980. As well as the cholera pandemic of the 18th century. Not to mention the swine flu in 1918, due to H1N1 virus, that supposedly killed around 50 million people.

Nevertheless in the last 100 years we have not had a very impressive pandemic, so considered the widespread occurrence of a disease, affecting all regions of the world, usually infectious and serious, not until 2009 when we had a resurgence of influenza viral pandemic of relatively mild virulence, which prompted a vaccine development against it.

And also in the 21 st century threatening epidemic from coronavirus were detected causing a serious respiratory infection in China and few other countries, by SARS-CoV and in the middle orient by the MERS-CoV- in 2003 and 2012 respectively.

All this led Bill Gates to alert the world that what should be a threat to humanity would not be a nuclear war, but viral pandemics.

But the world did not pay attention to this prediction, although it came from a very serious genius of our time.

Instead it continued to pursue the processes with all aiming results in which cuts and adjustments for cost containment were in order. In light of this view storage is a part less considered.

As a result the great potencies of the world were caught short of supplies of all that matters in facing a pandemic like the COVID-19 such as mechanical ventilators, personal protection equipment -PPEs-, intensive care unit beds, health personal and even supplies.

On the other hand all of the basic scientific knowledge that was being gathered related to the two recent coronavirus epidemics alluded above, was not stimulated, and thus an opportunity to have a better preparedness regarding specific treatment was missed.

Which has much to do with the way that scientific knowledge has been developed lately always searching for an immediate, lucrative result. Which penalizes the progress in basic knowledge.

Thus, there should not have been a surprise with the COVID-19 pandemic.

The world should have been better prepared to face its explosive appearance.

We hope that at the end of this pandemic, when a vaccine arrives, the world takes the opportunity to counterbalance the suffering caused by so many life losses and turn an appreciative look of thankfulness to the health professionals that faced this war, with determination and personal suffering, including many deaths among them, and also that science should prevail among all considerations in the biological and medical arena.

And recognize, once and for all, that for humanity health is what matters most.

Received on 30 May 2020; revised 15 June 2020.Address for correspondence: Dr. Gilson Soares Feitosa. Praça Conselheiro Almeida Couto, 500 - Nazaré. Phone: 5571 2203-8444. Zip Code: 40050-410. Salvador, Bahia, Brazil. E-mail: gilson-feitosa@ uol.com.br.

J Bioeng. Tech. Appl. Health 2020;3(2):123. (0) 2020 by SENAI CIMATEC. All rights reserved. 